\title{
Internet of things: A scientometric assessment of global output, 2005-2014
}

\author{
B. M. Gupta*, S. M. Dhawan', Ritu Gupta ${ }^{2}$ \\ National Institute of Science, Technology and Development Studies, ${ }^{1}$ National Physical Laboratory, New Delhi, ${ }^{2}$ Shri Venkateshwara \\ University, Tirupati, Andhra Pradesh, India
}

\begin{abstract}
The publication examines 6800 global publications on "Internet of Things" (loT), as covered in Scopus database during 2005-2014, experiencing an annual average growth rate of $98.63 \%$ and citation impact of 1.97 . The global publications on IoT came from several countries, of which the top 12 (China - 44.87\%, USA - 8.04\%, Germany - 6.06\%, Italy - 5.19\%, UK - 4.84\%, Spain - 4.19\%, France - 3.46\%, Taiwan - 2.53\%, South Korea - 2.34\%, Switzerland - 2.16\%, Finland $-2.03 \%$, and India - $1.87 \%$ ) together accounts for $87.57 \%$ and $89.56 \%$ share of the global publication and citations output during 2005-2014. Only $27.96 \%$ of the total global publications were cited one or more times during 2005-2014. Among subjects contributing to loT, computer science contributed the highest publication share (64.93\%), followed by engineering (43.01\%), social sciences $(4.65 \%)$, business, management and accounting (3.73\%), physics (2.94\%), and decision science (2.72\%) during 2005-2014. Under broad subjects, the major priorities have been assigned to hardware (technology) with $43.87 \%$ share, followed by applications (42.93\% share), architectural aspects of technology (22.69\% share), security aspects $(17.43 \%$ share), software (technology) $(7.10 \%$ share), privacy $(6.13 \%$ share), business models $(0.85 \%$ share), governance $(0.62 \%$ share), legal aspects and accountability $(0.5 \%$ share), etc. Among the various organizations and authors contributing to loT, the 20 most productive organizations and authors together contributed $16.78 \%$ and $6.13 \%$ publications share and $25.63 \%$ and $23.16 \%$ citation share to the cumulative global publications and citations output during 2005-2014. The top 15 most productive journals contributed $24.54 \%$ share to the total journal global publication output during 2005-2014, with largest number of papers (55) is published in Jisuanji Xuebao Chinese Journal of Computers, followed by International Journal of Distributed Sensor Network (50), Sensors Switzerland (46), China Communication (34), Wireless Personnel Communication (33), IEEE Sensors Journal (28), etc. There were only 10 highly cited papers (which came from 8 countries and involved 24 institutions and 41 authors), which had received 100 or more citations, and together got 2951 citations during 2005-2014.
\end{abstract}

Keywords: Global publications, Internet of Things, scientometrics

\section{INTRODUCTION}

Internet of Things (IoT) is about connecting world of smart things, homes, and cities of the future. This connectedness is between various things through Internet. In the future,

*Address for correspondence:

E-mail: bmgupta1@gmail.com

\begin{tabular}{|l|l|}
\hline \multicolumn{2}{|c|}{ Access this article online } \\
\hline Quick Response Code: & Website: \\
\hline & www.jscires.org \\
\cline { 2 - 3 } & \\
\hline
\end{tabular}

most homes, cities, and things will be connected through the internet. This has brought a fundamental change in which physical objects are developed, worked, or utilized. According to Gartner, there will be 26 million devices on the IoT by 2020 .

This is an open access article distributed under the terms of the Creative Commons Attribution-NonCommercial-ShareAlike 3.0 License, which allows others to remix, tweak, and build upon the work non-commercially, as long as the author is credited and the new creations are licensed under the identical terms.

For reprints contact: reprints@medknow.com

How to cite this article: Gupta BM, Dhawan SM, Gupta R. Internet of things: A scientometric assessment of global output, 2005-2014. J Sci Res 2015;4:104-14. 
The term Io T was popularized by the work of the Auto-ID Center at the Massachusetts Institute of Technology (MIT), which in 1999 started to design and propagate a cross-company radio frequency identification (RFID) infrastructure. ${ }^{[1]}$ In 2002, its co-founder and former head Kevin Ashton was quoted in Forbes Magazine as saying, "We need the Internet for things, a standardized way for computers to understand the real-world." "[2] This article was entitled "The Internet of Things," and was the first documented use of the term in a literal sense. ${ }^{[3]}$ However, already in 1999, essentially the same notion was used by Neil Gershenfeld from the MIT Media Lab in his popular book "When Things Start to Think" ${ }^{[1]}$ when he wrote "in retrospect it looks like the rapid growth of the World Wide Web may have been just the trigger charge that is now setting off the real explosion, as things start to use the Net." In recent years, the term "Io T" has spread rapidly - in 2005, it could already be found in book titles, conference proceedings, numerous articles in journals, international, regional, and national research programs, and independent journals. ${ }^{[3-6]}$

The IoT usually refers to a world-wide network of interconnected heterogeneous objects (sensors, actuators, smart - devices or objects or components or products, RFID, embedded computers, etc.) uniquely addressable, based on standard communication protocols. Beyond such a definition, it is emerging a new definition of IoT seen as a loosely coupled, decentralized system of cooperating smart objects (SOs). An SO is an autonomous, physical digital object augmented with sensing/actuating, processing, storing, and networking capabilities. SOs can sense/actuate, store, and interpret information created within themselves and around the neighbouring external world where they are situated, act on their own, cooperate with each other, and exchange information with other kinds of electronic devices and human users. However, such SO-oriented IoT raises many in-the-small and in-the-large issues involving SO programming, IoT system architecture/middleware, and methods/methodologies for the development of SO-based applications. ${ }^{[7]}$

"Smart" products play a key role in the Io'T vision. Smart products have three core elements: physical components, "smart" elements, and connectivity elements. Smart components amplify the capabilities and value of the physical elements, while connectivity amplifies the capabilities and value of the smart components and enable some of them to exist outside the physical product itself. Physical components comprise the mechanical and electrical parts, whereas smart components comprise the sensors, microprocessors, data storage, controls, software, and typically, an embedded operating system and enhanced user interface. Connectivity components comprise the ports, antennae, and protocols enabling wired or wireless connections with the product. Connectivity takes three forms, which can be present together: (i) One-to-one, (ii) one-to-many, and (iii) many-to-many. Connectivity serves a dual purpose. First, it allows information to be exchanged between the product and its operating environment, its maker, its users, and other products and systems. Second, connectivity enables some functions of the product to exist outside the physical device, in what is known as the product cloud. "Digitally upgrading" conventional object in this way enhances their physical function by adding the capabilities of digital objects, thus generating substantial added value. ${ }^{[8]}$

Forerunners of this development are already apparent today - more and more devices such as sewing machines, exercise bikes, electric toothbrushes, washing machines, electricity meters, and photocopiers are being "computerized" and equipped with network interfaces. In other application domains, Internet connectivity of everyday objects can be used to remotely determine their state so that information systems can collect up-to-date information on physical objects and processes. This enables many aspects of the real world to be "observed" at a previously unattained level of detail and at negligible cost. This would not only allow for a better understanding of the underlying processes, but also for more efficient control and management. ${ }^{[9]}$ The ability to react to events in the physical world in an automatic, rapid, and informed manner not only opens up new opportunities for dealing with complex or critical situations, but also enables a wide variety of business processes to be optimized. The real-time interpretation of data from the physical world will most likely lead to the introduction of various novel business services and may deliver substantial economic and social benefits.

From a technical point of view, the IoT is not the result of a single novel technology; instead, several complementary technical developments provide capabilities that taken together help to bridge the gap between the virtual and physical world. These capabilities include: (i) Communication and cooperation: Objects have the ability to network with Internet resources or even with each other, to make use of data and services and update their state. Wireless technologies such as GSM and UMTS, 
Wi-Fi, Bluetooth, ZigBee, and various other wireless networking standards currently under development, particularly those relating to Wireless Personal Area Networks, are of primary relevance here; (ii) addressability: Within an IoT, objects can be located and addressed via discovery, look-up or name services, and hence remotely interrogated or configured; (iii) identification: Objects are uniquely identifiable. RFID, near-field communication (NFC), and optically readable bar codes are examples of technologies with which even passive objects that do not have built-in energy resources can be identified (with the aid of a "mediator" such as an RFID reader or mobile phone). Identification enables objects to be linked to information associated with the particular object and that can be retrieved from a server, provided the mediator is connected to the network; (iv) Sensing: Objects collect information about their surroundings with sensors, record it, forward it, or react directly to it; (v) actuation: Objects contain actuators to manipulate their environment (for example, by converting electrical signals into mechanical movement). Such actuators can be used to remotely control real-world processes via the Internet; (vi) embedded information processing: SOs feature a processor or micro-controller, plus storage capacity. These resources can be used, for example, to process and interpret sensor information, or to give products a "memory" of how they have been used; (vii) localization: Smart things are aware of their physical location, or can be located. GPS or the mobile phone network are suitable technologies to achieve this, as well as ultrasound time measurements, ultra-wideband, radio beacons (e.g. neighbouring Wireless Local Area Networks base stations or RFID readers with known coordinates) and optical technologies; and (viii) User interfaces: SOs can communicate with people in an appropriate manner (either directly or indirectly, for example, via a smartphone). Innovative interaction paradigms are relevant here, such as tangible user interfaces, flexible polymer-based displays and voice, image or gesture recognition methods. ${ }^{[10]}$

\section{Literature Review}

In the past, very few scientometric studies have been carried on publication and patent data on IoT both at global and national levels. Whitmore et al. ${ }^{[1]}$ reported on the current state of research, based on the analysis of 127 publications on the IoT. They examined the literature, identified current trends, described challenges that threaten IoT diffusion, and presented open research questions and future directions. The literature was classified according to its content into major categories: Technology, applications, challenges, business models, future directions, and overview/survey. Some of these top-level categories were further broken down into sub-categories, and some of the sub-categories were broken into sub-sub-categories.

A report by World Intellectual Property Organization ${ }^{[12]}$ analyzed the global patents filed on IoT during 2003-2012, focusing on the geographical distribution of patents, distribution of patent filing across top assignees, and broad subject-wise distribution. The patent subject portfolio has been divided into four broad categories: Networking, computing, infrastructure, and application areas; (i) networking - resource management, computing protocols, topology, and management, (ii) computing has been subdivided into information retrieval, imaging processes, and data security, (iii) infrastructure - control system, circuits, and sensors and (iv) applications - E-commerce, home security, health care, etc. Another report from Intellectual Office of $\mathrm{UK}^{[13]}$ analyzed 22,000 published patents (which belongs to 9860 patent families, involving 7238 patent assignees and 17,756 inventors from 42 countries on IoT during 2004-2013. The main analysis provides break-up of patents data by period, distribution across countries, identification of top assignees, technology break down by IPC Group, and the extent of international collaboration involved.

\section{OBJECTIVES}

The main objectives of this study are to study the performance of global research on IoT during 2005-2014, based on publications output, as indexed in Scopus database. In particular, the study focuses on the following objectives:

- To study the growth of world literature and study its distribution by type of documents and sources;

- To study the citation pattern of the global research output;

- To study the contribution, global share, and citation impact of top 12 most productive countries;

- To study the distribution of global research output by broad subject areas and by narrow subfields and identification of significant keywords;

- To study the publication productivity and citation impact of most productive top 20 organizations and authors;

- To study the leading media of communication; and

- To study the characteristics of highly cited papers. 


\section{METHODOLOGY}

The study retrieved and downloaded the publication data of the world and of 12 most productive countries on IoT from the Scopus database (http://www.scopus.com) for 10 years during 2005-2014. The keyword IoT was used in "title, abstract, and keyword" tag and restricting it to the period 2005-2014 in "date range tag" for searching the global publication data and this become the main search string. When the main search string is restricted to 12 most productive countries in the "country tag," as shown below, the publication data on these individual most productive countries were obtained. When the main search string is further restricted to "subject area tag," "country tag," "source title tag," "journal title name," and "affiliation tag," we got information on distribution of publications by subject, collaborating countries, organization-wise and journal-wise, etc. The citation data were collected from the date of publication until the end of April 2015. There are a number of quantitative and qualitative indicators used for measuring the research activity. Among such indicators, Relative Citation Index (RCI) is defined as the ratio of global share of citations to global share of papers.

\section{ANALYSIS}

\section{World Output}

The cumulative research output on IoT reached 6800 publications in 10 years during 2005-2014. The cumulative annual average growth was $72.74 \%$. The cumulative output increased from 186 global publications on IoT during 2005-2009 to 6614 during 2010-2014, averaging 5 yearly growth rate of $3455.19 \%$. The average citation per paper averaged to 1.97 during 2005-2014 [Table 1 and Figure 1].

\section{Distribution of Citations}

The global publications output of 6800 papers on IoT during 2005-2014 received 13,397 citations until 20 April 2015. The average citation per publication was 1.97. Around $69 \%$ of the total publications did not get any citations (zero citation) in 11 years and the rest $31.02 \%$ publications were cited one or more times. Of the total cited publications, $27.96 \%$ publications (receiving 1-10 citations) accounted for $37.98 \%$ citations share, $2.00 \%$ publications (receiving $11-30$ citations) contributed $16.89 \%$ citations share, $0.51 \%$ publications each (receiving 31-50 citations) contributed $10.31 \%$ citation share, $0.40 \%$ publications (receiving 51-100 citations) contributed $13.82 \%$ citation share, and the rest $0.14 \%$ publications (receiving $>100$ ) contributed $21.00 \%$ citations share [Table 2 and Figure 2].

\section{Global Publication Share of Top 12 Most Productive Countries}

The top 12 most productive countries on IoT contributed individually from 127 to 3051 papers and together contributed 5955 papers and 11,988 citations, accounting for $87.57 \%$ global publications share and $89.56 \%$ citations share of the total output during 2004-2013. The largest global publication share $(44.87 \%)$ came from China, followed by USA (8.04\%), Germany $(6.06 \%)$, Italy (5.19\%), UK (4.84\%), Spain (4.19\%), France (3.46\%), Taiwan (2.53\%), South Korea (2.34\%), Switzerland (2.16\%), Finland (2.03\%), and India (1.87\%) during 2005-2014. The highest average citation per paper impact (6.44) was made by Italy from among the top 12 most productive countries, followed by Switzerland (6.02), Finland (4.31), UK (3.71), Spain (2.99), USA (2.14), Germany (2.09), France (1.94),

\begin{tabular}{|c|c|c|c|}
\hline Period & TP & TC & ACPP \\
\hline 2005 & 10 & 12 & 1.2 \\
\hline 2006 & 17 & 148 & 8.706 \\
\hline 2007 & 21 & 71 & 3.381 \\
\hline 2008 & 50 & 219 & 4.38 \\
\hline 2009 & 88 & 999 & 11.35 \\
\hline 2010 & 388 & 3933 & 10.14 \\
\hline 2011 & 819 & 2678 & 3.27 \\
\hline 2012 & 1271 & 2542 & 2.00 \\
\hline 2013 & 1771 & 1991 & 1.124 \\
\hline 2014 & 2365 & 784 & 0.332 \\
\hline 2005-2009 & 186 & 1449 & 7.79 \\
\hline $2010-2014$ & 6614 & 11,928 & 1.80 \\
\hline 2005-2014 & 6800 & 13,377 & 1.97 \\
\hline
\end{tabular}

Table 2: Citations received by global publications on "Internet of Things" during 2005-2014

\begin{tabular}{lcccc}
\hline $\begin{array}{l}\text { Citation } \\
\text { range }\end{array}$ & $\begin{array}{c}\text { Number } \\
\text { of papers }\end{array}$ & $\begin{array}{c}\text { Number of } \\
\text { citations }\end{array}$ & $\begin{array}{c}\text { Share of } \\
\text { papers }\end{array}$ & $\begin{array}{c}\text { Share of } \\
\text { citations }\end{array}$ \\
\hline 0 & 4691 & 0 & 68.98 & 0.00 \\
$1-10$ & 1901 & 5088 & 27.96 & 37.98 \\
$11-30$ & 136 & 2263 & 2.00 & 16.89 \\
$31-50$ & 35 & 1381 & 0.51 & 10.31 \\
$51-100$ & 27 & 1851 & 0.40 & 13.82 \\
$101-200$ & 7 & 1134 & 0.10 & 8.465 \\
$201-300$ & 2 & 483 & 0.03 & 3.605 \\
$>300$ & 1 & 1197 & 0.01 & 8.935 \\
& 2109 & 13,397 & 31.02 & 100 \\
\hline
\end{tabular}


Taiwan (1.40), South Korea (1.38), India (1.33), and China (1.00) during 2005-2014. In terms of RCI, above the world average value of 1 was achieved by Italy (3.28), Switzerland (3.06), Finland (2.19), UK (1.89), Spain (1.52), USA (1.09), and Germany (1.06). The other countries that averaged RCI value below 1 were France (0.99), Taiwan (0.71), South Korea (0.70), India (0.68), and China (0.51) during 2005-2014 [Table 3 and Figure 3].

\section{Subject-wise distribution of papers}

As per Scopus database classification, computer science accounted for the highest publications share $(64.93 \%)$ of the global publications on IoT during 2005-2014, followed by engineering (43.01\%), social sciences (4.65\%), business, management and accounting (3.73\%), physics (2.94\%), and decision science (2.72\%) during 2005-2014 [Table 4].

Among these six subjects, decision sciences registered the highest average citation per paper impact (3.72), followed

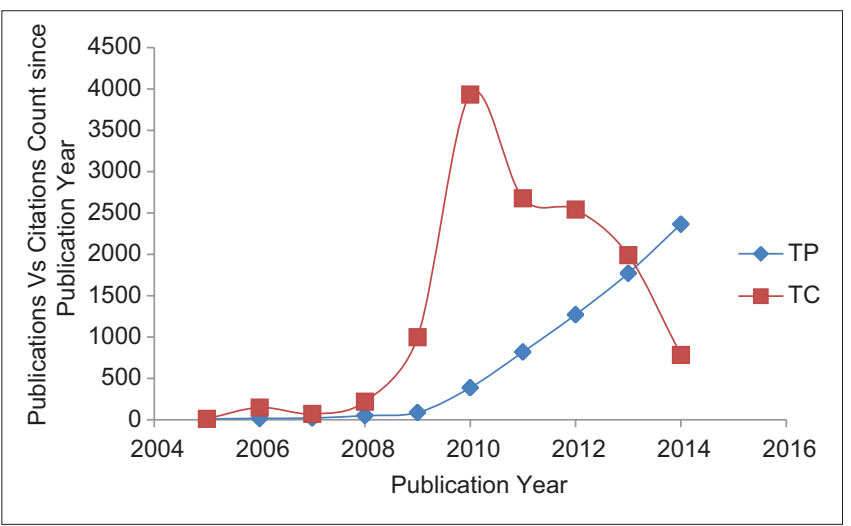

Figure 1: Distribution of publications output on Internet of Things by publication year: 2005-2014 by physics (2.78), computer science (2.41), business, management and accounting (2.11), engineering (1.81), and social sciences (1.61) during 2005-2014.

\section{Subfield-wise break-up of publications}

Under the IoT, major emphasis has been placed on technology. The hardware aspects of technology accounted for 2983 papers (43.87\%): RFID (1394 papers), NFC (82 papers), sensor network (1296 papers), actuators (211 papers), and internet protocol including IPv6 (649 papers) during 2005-2014. The software aspects of technology accounted for 483 papers $(7.10 \%)$ : Middleware (321 papers) and searching/browsing (172 papers) during 2005-2014. The architectural aspects of technology accounted for 1543 (22.69\%) papers during 2005-2014. The second important area is the applications that accounted for 2919 (42.93\%) papers: Industry, factory, and manufacturing (1050 papers), transportation and

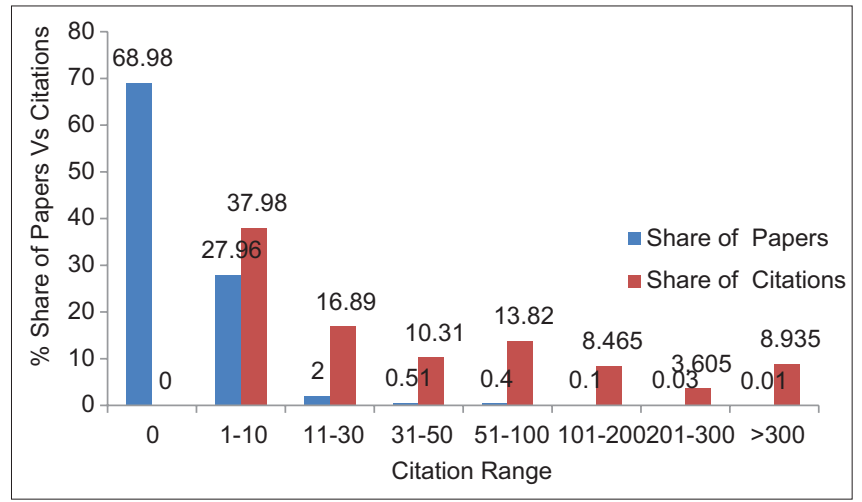

Figure 2: Distribution of publications on Internet of Things by citation range: $2005-2014$

Table 3: Global publication output, global publication share, and citation impact of top 12 countries on "Internet of Things" during 2005-2014

\begin{tabular}{lcccccccc}
\hline Country & TP & TC & ACPP & Percentage of TP & Percentage of TC & RCI & ICP & Percentage of ICP \\
\hline China & 3051 & 3056 & 1.00 & 44.87 & 22.85 & 0.51 & 277 & 9.079 \\
USA & 547 & 1170 & 2.14 & 8.044 & 8.746 & 1.09 & 259 & 47.35 \\
Germany & 412 & 861 & 2.09 & 6.059 & 6.436 & 1.06 & 137 & 33.25 \\
Italy & 353 & 2275 & 6.44 & 5.191 & 17.01 & 3.28 & 103 & 29.18 \\
UK & 329 & 1221 & 3.71 & 4.838 & 9.128 & 1.89 & 173 & 52.58 \\
Spain & 285 & 851 & 2.99 & 4.191 & 6.362 & 1.52 & 109 & 38.25 \\
France & 235 & 456 & 1.94 & 3.456 & 3.409 & 0.99 & 104 & 44.26 \\
Taiwan & 172 & 240 & 1.40 & 2.529 & 1.794 & 0.71 & 37 & 21.51 \\
South Korea & 159 & 219 & 1.38 & 2.338 & 1.637 & 0.70 & 32 & 20.13 \\
Switzerland & 147 & 885 & 6.02 & 2.162 & 6.616 & 3.06 & 73 & 49.66 \\
Finland & 138 & 595 & 4.31 & 2.029 & 4.448 & 2.19 & 66 \\
India & 127 & 169 & 1.33 & 1.868 & 1.263 & 0.68 & 22 \\
World & 6800 & 13,377 & 1.97 & & & 47.83 & 17.32
\end{tabular}

$\mathrm{TP}=$ Total papers, $\mathrm{TC}=$ Total citations, $\mathrm{ICP}=$ International collaborative papers, $\mathrm{RCI}=$ Relative citation index 
vehicles (517 papers), health (450 papers), smart home (430 papers), social media and networking (308 papers), logistics (270 papers), smart city (325 papers), environment monitoring (306 papers), smart power grid (300 papers), supply chain (281 papers), smart buildings (243 papers), education (213 papers), agriculture including irrigation and farming (181 papers), water (155 papers), energy monitoring (87 papers) during 2005-2014. The third form for the challenges faced: Security (1185 papers, $17.43 \%$ ), privacy (417 papers, $6.13 \%$ ), legal aspects

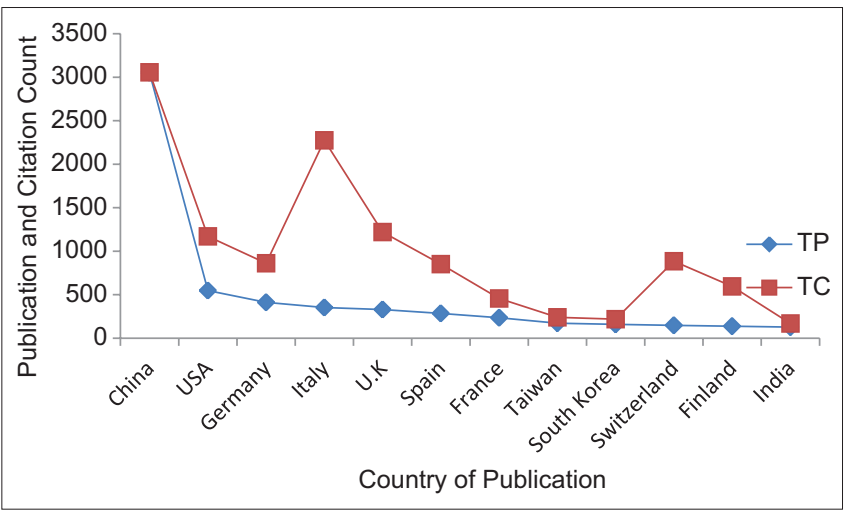

Figure 3: Distribution of publications on Internet of Things by country of publication: 2005-2014

Table 4: Subject-wise break-up of global publications on "Internet of Things" during 2005-2014

\begin{tabular}{lcccc}
\hline Name of the subject & TP & TC & ACPP & Percentage of TP \\
\hline Computer science & 4415 & 10643 & 2.41 & 64.93 \\
Engineering & 2925 & 5296 & 1.81 & 43.01 \\
Social science & 316 & 508 & 1.61 & 4.647 \\
$\begin{array}{l}\text { Business, management } \\
\text { and accounting }\end{array}$ & 254 & 535 & 2.11 & 3.735 \\
Physics & 200 & 555 & 2.78 & 2.941 \\
Decision sciences & 185 & 688 & 3.72 & 2.721 \\
& 6800 & & & \\
\hline
\end{tabular}

$\overline{\mathrm{TP}}=$ Total papers, $\mathrm{TC}=$ Total citations, $\mathrm{ACPP}=$ Average citations per paper and accountability (34 papers, $0.5 \%$ ), and governance (42 papers, $0.62 \%$ ), and among other areas include business models (58 papers, 0.85\%) during 2005-2014. The priorities given to these subfields in terms of output in top 12 most productive countries are shown in Table 5.

\section{Significant keywords}

A list of top 86 most frequently used keywords on global literature on IoT is shown in Table 6, along with frequency of their occurrence as shown in Table 5. The largest frequency of occurrence (5657) was for Io'T, followed by internet (3112), architecture (1538), RFID (1394), sensor network (1295), security (1185), wireless sensor network (722), etc.

\section{Profile of top 20 most productive organizations}

The productivity of 20 most productive organizations in IoT varied from 37 to 194 publications and together they contributed $16.781 \%$ (1141) publications share and $25.63 \%$ (3429) citation share in the cumulative global publications output in IoT research during 2005-2014. The scientometric profile of these 20 organizations is presented in Table 7.

Six organizations registered higher publications output than the group average of 57.05: Beijing University of Posts and Telecommunications, China (194 publications), Beijing Jiatong Daxue, China (69 publications), Universidad de Murcia, Spain (66 publications), Institute of Computing Research, Chinese Academy of Sciences, China (63 publications), Nanjing University of Posts and Telecommunications, China (62 publications), and Tsinghua University, China (62 publications). Six organizations have registered more than the average citation per publication (3.00) of 20 organizations: Eidgenossische Technische Hochschute, Zurich, Switzerland (13.10),

Table 5: Subfield-wise break-up of global publications on "Internet of Things" during 2005-2014

\begin{tabular}{|c|c|c|c|c|c|c|c|c|c|c|c|c|}
\hline \multirow[t]{2}{*}{ Subfields } & \multicolumn{12}{|c|}{ Number of papers } \\
\hline & China & USA & Germ & Italy & UK & Spain & France & Taiwan & South Korea & Switzerland & Finland & India \\
\hline Tech-hardware & 1269 & 242 & 176 & 170 & 123 & 141 & 105 & 90 & 68 & 77 & 53 & 62 \\
\hline Tech-software & 183 & 31 & 32 & 40 & 11 & 14 & 30 & 20 & 8 & 9 & 11 & 9 \\
\hline Tech-architect & 585 & 101 & 110 & 117 & 86 & 95 & 71 & 39 & 43 & 45 & 40 & 26 \\
\hline Applications & 1302 & 234 & 197 & 145 & 138 & 130 & 83 & 62 & 47 & 68 & 46 & 53 \\
\hline Security & 531 & 85 & 66 & 37 & 54 & 54 & 34 & 18 & 31 & 23 & 23 & 42 \\
\hline Privacy & 147 & 39 & 32 & 15 & 24 & 22 & 18 & 2 & 10 & 13 & 8 & 15 \\
\hline Legal/account & 8 & 2 & 4 & 1 & 1 & 1 & 3 & 0 & 0 & 5 & 0 & 1 \\
\hline Governance & 8 & 3 & 4 & 2 & 5 & 0 & 2 & 0 & 0 & 0 & 0 & 0 \\
\hline Business models & 21 & 5 & 8 & 7 & 2 & 4 & 3 & 2 & 0 & 3 & 2 & 0 \\
\hline Total of the country & 3051 & 547 & 412 & 353 & 329 & 285 & 235 & 172 & 159 & 147 & 138 & 127 \\
\hline
\end{tabular}


University of Surrey, UK (6.72), Tsinghua University, China (5.71), Huazhong University of Science and Technology, China (5.17), NIPER-Mohali Institute of Computing Research, Chinese Academy of Sciences, China (4.24), and Shanghai Jiatong University, China (4.09) during 2005-2014. Eight organizations have registered more than the average h-index (5.80) of all 20 organizations: University of Surrey, UK (10), Eidgenossische Technische Hochschute, Zurich, Switzerland (9), Institute of Computing Research, Chinese Academy of Sciences, China and Nanjing University of Posts and Telecommunications, China (8 each), Tsinghua University, China, Huazhong University of Science and Technology, China, Shanghai Jiatong University, China and Beijing University of Posts and Telecommunications, China (7 each) during 2005-14. Eight organizations have achieved more than the average share of international collaborative publications $(21.60 \%)$ of all 20 organizations: University of Surrey, UK $(73.90 \%)$, Shanghai Jiatong University, China (52.80\%), Aalto
University, Finland (46.80\%), Eidgenossische Technische Hochschute, Zurich, Switzerland (46.20\%), Institute of Computing Research, Chinese Academy of Sciences, China (36.50\%), Huazhong University of Science and Technology, China (35.00\%), Universidad de Murcia, Spain (27.30\%), and Tsinghua University, China (24.20\%) during 2004-2013.

\section{Profile of the top 20 most productive authors}

The top 20 most productive authors published 14-60 publications each in 10 years and together contributed $6.13 \%$ publication share and $23.16 \%$ citation share to the cumulative global publications output in IoT during 2005-2014. The scientometric profile of these 20 authors is presented in Table 8. Six authors have registered higher publications per author than the group average (20.85): A. J. Jara (60 publications), A. F. Skarmeta (54 publications), L. D. Xu (26 publications), R. Prasad (22)

Table 6: Frequency distribution of most significant keywords in global literature on IoT used during 2005-2014

\begin{tabular}{|c|c|c|c|c|c|}
\hline Name of keyword & Frequency & Name of keyword & Frequency & Name of keyword & Frequency \\
\hline IoT & 5657 & Intelligent building & 240 & RFID tags & 86 \\
\hline Internet & 3112 & Energy utilization & 218 & Near field communication & 82 \\
\hline Architecture & 1538 & Smart objects & 218 & System architecture & 68 \\
\hline RFID & 1394 & Supply chain & 213 & Security systems & 66 \\
\hline Sensor network & 1295 & Smart city & 214 & Software engineering & 64 \\
\hline Security & 1185 & RFID technology & 211 & IPv6 & 63 \\
\hline Wireless sensor networks & 722 & Network security & 203 & Environment monitoring & 62 \\
\hline Sensor & 572 & Healthcare & 201 & Factory automation & 59 \\
\hline Internet protocols & 649 & Electronic commerce & 192 & Energy conservation & 50 \\
\hline Building & 624 & Social network & 184 & Traffic management & 49 \\
\hline Home & 426 & Industry & 182 & Computer architecture & 48 \\
\hline Manufacturing & 430 & Cryptography & 181 & Vehicles & 47 \\
\hline Privacy & 417 & Energy efficiency & 178 & Energy harvesting & 46 \\
\hline Home & 426 & Smart home & 177 & Industrial management & 44 \\
\hline Ubiquitous computing & 405 & Security data & 156 & Software architecture & 42 \\
\hline City & 384 & Wireless sensor & 154 & Actuators & 40 \\
\hline Telecommunication networks & 383 & Artificial intelligence & 141 & Commerce & 40 \\
\hline Smart power grid & 350 & Smart devices & 124 & Agricultural production & 35 \\
\hline Information management & 347 & Authentication & 122 & Industrial applications & 32 \\
\hline Middleware & 321 & Data privacy & 121 & Intelligent transport system & 25 \\
\hline Network architecture & 313 & Smart home & 119 & Irrigation & 24 \\
\hline Cloud computing & 321 & Digital storage & 116 & Environment monitoring & 24 \\
\hline Algorithms & 320 & Cryptography & 103 & Smart meters & 20 \\
\hline Wireless telecommunication networks & 318 & Healthcare & 102 & Greenhouse & 15 \\
\hline Network architecture & 314 & Service oriented architecture & 96 & Farming & 15 \\
\hline Sensor networks & 302 & Smart environment & 94 & Temperature monitoring & 15 \\
\hline Transportation & 275 & Mobile telecommunications & 91 & Humidity control & 11 \\
\hline Smart phone & 262 & Logistics & 90 & Water management & 11 \\
\hline Automation & 260 & Agriculture & 89 & & \\
\hline
\end{tabular}

RFID $=$ Radio frequency identification, IoT = Internet of Things 
Table 7: Scientometric profile of the 20 top most productive organizations on "Internet of Things" during 2005-2014

\begin{tabular}{|c|c|c|c|c|c|c|}
\hline Name of organization & TP & TC & ACPP & ICP & Percentage of ICP & $\mathrm{HI}$ \\
\hline Beijing University of Posts and Telecommunications, China & 194 & 325 & 1.675 & 18 & 9.28 & 7 \\
\hline Beijing Jiatong Daxue, China & 69 & 42 & 0.609 & 5 & 7.25 & 4 \\
\hline University of Murcia, Spain & 66 & 187 & 2.833 & 18 & 27.3 & 6 \\
\hline Institute of Computing Research, Chinese Academy of Sciences, China & 63 & 267 & 4.238 & 23 & 36.5 & 8 \\
\hline Nanjing University of Posts and Telecommunications, China & 62 & 171 & 2.758 & 5 & 8.06 & 8 \\
\hline Tsinghua University, China & 62 & 354 & 5.71 & 15 & 24.2 & 7 \\
\hline Shanghai Jiao tong University, China & 53 & 217 & 4.094 & 28 & 52.8 & 7 \\
\hline Eidgenossische Technische Hochschute, Zurich, Switzerland & 52 & 681 & 13.1 & 24 & 46.2 & 9 \\
\hline Wuhan University of Technology, China & 51 & 67 & 1.314 & 4 & 7.84 & 4 \\
\hline Wuhan University, China & 51 & 68 & 1.333 & 11 & 21.6 & 4 \\
\hline Aalto University, Finland & 47 & 99 & 2.106 & 22 & 46.8 & 5 \\
\hline University of Surrey, UK & 46 & 309 & 6.717 & 34 & 73.9 & 10 \\
\hline University of Science and Technology, Beijing, China & 45 & 72 & 1.6 & 5 & 11.1 & 5 \\
\hline Jilin University, China & 44 & 77 & 1.75 & 2 & 4.55 & 5 \\
\hline South China University of Technology, China & 42 & 113 & 2.69 & 4 & 9.52 & 5 \\
\hline Huazhong University of Science and Technology, China & 40 & 207 & 5.175 & 14 & 35 & 7 \\
\hline Hunan First Normal University, China & 40 & 25 & 0.625 & 4 & 10 & 3 \\
\hline Northwestern Polytechnic University, China & 39 & 72 & 1.846 & 5 & 12.8 & 5 \\
\hline Tongji University, China & 38 & 37 & 0.974 & 4 & 10.5 & 4 \\
\hline Harbin Institute of Technology, China & 37 & 39 & 1.054 & 1 & 2.7 & 3 \\
\hline Total of 20 top organizations & 1141 & 3429 & 3.005 & 246 & 21.6 & 5.8 \\
\hline Total of the world & 6800 & 13,377 & & & & \\
\hline Share of top 20 organizations in global output & 16.78 & 25.63 & & & & \\
\hline
\end{tabular}

$\mathrm{TP}=$ Total papers, $\mathrm{TC}=$ Total citations, $\mathrm{ACPP}=$ Average citations per paper, $\mathrm{ICP}=$ International collaborative papers; $\mathrm{HI}=\mathrm{H}$-index

I. Moermon (18), and M. A. Zamora (18). Four authors have registered more than the average citation per publication (7.43) of all 20 authors: L. Atzori (90.33), L. D. Xu (10.81), A. Gluhak (10.25), and M. Zorzi (9.14) during 2005-2014. Five authors have registered more than the average h-index (4.10) of all authors during 2003-2012: L. D. Xu (8), A. Zaslavsky (7), A. J. Jara (6), L. Atzori (5), and A. F. Skarmeta (5) during 2005-2014. Ten authors have achieved more than the average share of international collaborative publications $(36.69 \%)$ of all 19 authors: N. Bessis $(80.00 \%)$, Q. Z. Sheng $(75.00 \%)$, A. Gluhak and S. Krco (68.75\% each), K. Moessner (64.29\%), P. Barnaghi (62.50\%), L. D. Xu and R. Prasad (50\% each), W. Wang (40.00\%), and A. J. Jara (38.33\%) during 2005-2014.

\section{Medium of communication}

Of the 6800 papers on IoT, 3357 had appeared in conference proceedings, 1801 in Journals, 1488 in book series, 111 in trade publications, and 43 as books during 2005-2014. The 15 most productive journals contributed from 18 to 55 papers and together contributed 24.54\% share (442 papers) to the total journal publication output in 2005-2014. The largest number of papers (55) were published in Jisuanji Xuebao Chinese Journal of Computers, followed by International Journal of Distributed Sensor Network (50), Sensors Switzerland (46), China Communication (34), Wireless Personnel Communication (33), IEEE Sensors Journal (28), IEEE Transactions on Industrial Informatics (27), Ad-Hoc Networks (26), and Jisuanji Jicheng Zhizao Xitong. Computer Integrated Manufacturing System and Personal and Ubiquitous Computing (22 each), Advances in Information Sciences and Service Sciences, Jisuanji Yanju Yu Faz̧ban Computer Research and Development and Journal of Convergence Information Technology (20 each) and Tongxin Xuebao Journal of Communications (18) during 2005-2014.

\section{Highly cited papers}

In all, there were 10 highly cited papers with 100 or more citations since their publications until April 2015. Their citation distribution is skewed. Six papers out of 10 have registered citations from 124 to 199, 3 papers from 204 to 264, and 1 paper 1259 citations during 2005-2014. These 10 papers together have registered 2951 citations, with average citations per paper of 295.1 during 2005-2014. The 10 highly cited papers involve 8 countries, 24 institutions, and 41 authors, with 2 papers each from USA, Italy, Germany, and Switzerland and 1 paper each from China, 
Table 8: Scientometric profile of the top 20 authors on "Internet of Things," 2005-2014

\begin{tabular}{|c|c|c|c|c|c|c|c|}
\hline Name & Affiliation & TP & TC & ACPP & ICP & Percentage of ICP & HI \\
\hline A. J. Jara & University of Murcia, Spain & 60 & 184 & 3.067 & 23 & 38.33 & 6 \\
\hline A. F. Skarmeta & University of Murcia, Spain & 54 & 168 & 3.111 & 13 & 24.07 & 5 \\
\hline L. D. Xu & $\begin{array}{l}\text { Dominion University, USA and Institute of Computing } \\
\text { Technology, China }\end{array}$ & 26 & 281 & 10.81 & 13 & 50 & 8 \\
\hline M A. Zamora & University of Murcia, Spain & 24 & 123 & 5.125 & 1 & 4.167 & 4 \\
\hline R. Prasad & Aalborg University, Denmark & 22 & 41 & 1.864 & 11 & 50 & 3 \\
\hline I. Moermon & Ghent University, Belgium & 18 & 22 & 1.222 & 2 & 11.11 & 3 \\
\hline P. Demeester & Ghent University, Belgium & 17 & 20 & 1.176 & 2 & 11.76 & 3 \\
\hline S. Krco & Ericcson Serbia, Serbia & 16 & 65 & 4.063 & 11 & 68.75 & 2 \\
\hline A. Zaslavsky & $\begin{array}{l}\text { Commonwealth Scientific and Industrial Research } \\
\text { Organization, Canberra, Australia }\end{array}$ & 16 & 95 & 5.938 & 3 & 18.75 & 7 \\
\hline A. Gluhak & University of Surrey, UK & 16 & 164 & 10.25 & 11 & 68.75 & 4 \\
\hline Q. Z. Sheng & University of District of Columbia, Washington, D.C., USA & 16 & 59 & 3.688 & 12 & 75 & 4 \\
\hline W. Wang & University of Surrey, UK; Southeast University, Nanjing, China & 15 & 64 & 4.267 & 6 & 40 & 4 \\
\hline P. Barnaghi & University of Surrey, UK & 16 & 93 & 5.813 & 10 & 62.5 & 4 \\
\hline L. Atzori & University of Cagliari, Italy & 15 & 1355 & 90.33 & 1 & 6.667 & 5 \\
\hline N. Bessis & University of Derby, UK & 15 & 19 & 1.267 & 12 & 80 & 3 \\
\hline K. Framling & Helsinki University of Technology, Finland & 15 & 56 & 3.733 & 4 & 26.67 & 4 \\
\hline M. Zorzi & University of Padova, Italy & 14 & 128 & 9.143 & 4 & 28.57 & 4 \\
\hline K. Moessner & University of Surrey, UK & 14 & 58 & 4.143 & 9 & 64.29 & 3 \\
\hline J. Haupert & $\begin{array}{l}\text { German Research Center for Artificial Intelligence, } \\
\text { Saarbricken, Germany }\end{array}$ & 14 & 32 & 2.286 & 4 & 28.57 & 3 \\
\hline Z. Cheng & University of Aizu, Japan & 14 & 71 & 5.071 & 1 & 7.143 & 3 \\
\hline Total output & & 417 & 3098 & 7.429 & 153 & 36.69 & 4.1 \\
\hline Total global output & & 6800 & 13,377 & & & & \\
\hline $\begin{array}{l}\text { Share of } 20 \text { authors } \\
\text { in global output }\end{array}$ & & 6.13 & 23.16 & & & & \\
\hline
\end{tabular}

UK, Australia, and Finland during 2005-2014. Eight out of 10 publications were research articles, and 1 each was a review paper and one published as a book. Of the 10 highly cited papers, 2 were without any collaborative activity, 6 were national collaborative, and 2 international collaborative papers. The list of 10 highly cited papers is given in Table 9.

\section{SUMMARY AND CONCLUSION}

The IoT is a computing concept where all things, including every physical object, can be connected to the Internet, making those objects intelligent, programmable, and capable of interacting with each other and with humans. The term IoT is used to refer to "things" such as environments, buildings, vehicles, clothing, portable devices, and other objects that will have the ability to sense, analyze, communicate, network, and produce new information. Most of the physical objects in future will be connected with smart devices, networks, and infrastructure through the Internet. This sort of connectedness between various things has the potential to bring about the fundamental change in which they work, are developed, and are used. A widespread Io'T will revolutionize consumer habits and the way we do business. As more and more information is revealed each day, IoT will transform how we communicate with machines and each other can change the world. The IoT demonstrates how the communication and connection have moved from machine-to-machine (M2M), machine-to-human (M2H), machine-to-things (M2T), things-to-things (T2T), etc. IoT is more about smart devices and smart services that will change forever our personal and professional lives, how we live in our cities, how we travel, how we manage our lives sustainably, how we age, and how services and entertainment accompany us and adapt as our surroundings change.

The IoT research is multi-disciplinary in nature combining the study of electronic engineering and computer science, with an emphasis on internet technologies, wireless communications, sensor devices, and cloud computing. Research and development in this area are still in its infant stage of growth. The first research paper on Io'T 
Table 9: Top 10 highly cited papers on IoT during 2005-2014

\begin{tabular}{|c|c|c|c|c|}
\hline Name of authors & Affiliation of authors & Title of paper & Source & $\begin{array}{c}\text { Number of } \\
\text { citations }\end{array}$ \\
\hline $\begin{array}{l}\text { L. Atzori, A. lera, } \\
\text { G. Morabito }\end{array}$ & $\begin{array}{l}\text { University of Cagliari, DIEE, Italy; University } \\
\text { Mediterranean of Reggio Calabria, Italy and } \\
\text { University of Catania, Italy }\end{array}$ & The loT: A survey (article) & $\begin{array}{l}\text { Computer Networks } \\
2010 ; 54(15): 2787-805\end{array}$ & 1259 \\
\hline $\begin{array}{l}\text { B. H. Li, L. Zhang, } \\
\text { S. L. Wang, F. Tao, } \\
\text { J. W. Cao, X. D. Jiang, } \\
\text { X. Song, X. D. Chai }\end{array}$ & $\begin{array}{l}\text { Beihang University, Engineering Research Center } \\
\text { of Advanced Manufacturing System of Complex } \\
\text { Product, Beijing, China; Beijing Simulation Center, } \\
\text { China; College of Mechanical Engineering, } \\
\text { Chongqing University of Chongqing, China; } \\
\text { Research Institute of Information Technology, } \\
\text { Tsinghua University, Beijing China and Smartdot } \\
\text { Technologies Co. Ltd., Beijing, China }\end{array}$ & $\begin{array}{l}\text { Cloud manufacturing: } \\
\text { A new service-oriented } \\
\text { networked manufacturing } \\
\text { model (article) }\end{array}$ & $\begin{array}{l}\text { Jisuanji Jicheng } \\
\text { Zhizao Xitong/CIMS } \\
\text { 2010;16 (1):1-7, } 16\end{array}$ & 264 \\
\hline $\begin{array}{l}\text { G. Kortuem, F. Kawsar, } \\
\text { V. Sundramoorthy, } \\
\text { D. Fitton }\end{array}$ & $\begin{array}{l}\text { Lancaster University, UK, University of Central } \\
\text { Lancashire, UK and University of Salford, UK }\end{array}$ & $\begin{array}{l}\text { Smart objects as building } \\
\text { blocks for the loT (Article) }\end{array}$ & $\begin{array}{l}\text { IEEE Internet } \\
\text { Computing } \\
2010 ; 14(1): 44-51\end{array}$ & 241 \\
\hline $\begin{array}{l}\text { E. Welbourne, L. Battle, } \\
\text { G. Cole, K. Gould, } \\
\text { K. Rector, S. Raymer, } \\
\text { M. Balazinska, } \\
\text { G. Borriello }\end{array}$ & $\begin{array}{l}\text { University of Washington, Department of } \\
\text { Computer Science and Engineering Seattle, WA, } \\
\text { USA; Microsoft Research, USA; Western Oregon } \\
\text { University, Monmouth, OR, USA and Oregon } \\
\text { State University, Corvallis, OR, USA }\end{array}$ & $\begin{array}{l}\text { Building the loT } \\
\text { using RFID: The } \\
\text { RFID ecosystem } \\
\text { experience (article) }\end{array}$ & $\begin{array}{l}\text { IEEE Internet } \\
\text { Computing } \\
2009 ; 813 \text { (3): } 48-55\end{array}$ & 204 \\
\hline $\begin{array}{l}\text { D. Guinard, V. Trifa, } \\
\text { S. Karnouskos, } \\
\text { P. Spiess, D. Savio }\end{array}$ & $\begin{array}{l}\text { SAP Research and Institute for Pervasive } \\
\text { Computing, ETH Zurich, Switzerland and SAP } \\
\text { Research Karlsruhe, Germany }\end{array}$ & $\begin{array}{l}\text { Interacting with the } \\
\text { SOA-based loT: Discovery, } \\
\text { query, selection, and } \\
\text { on-demand provisioning of } \\
\text { web services (article) }\end{array}$ & $\begin{array}{l}\text { IEEE Transactions on } \\
\text { Services Computing } \\
\text { 2010;3 (3): 223-35 }\end{array}$ & 199 \\
\hline $\begin{array}{l}\text { D. Miorandi, S. Sicari, } \\
\text { F. De Pellegrini, } \\
\text { I. Chlamtac }\end{array}$ & $\begin{array}{l}\text { CREATE-NET, via Alla Cascata 56/D, IT-38123 } \\
\text { Povo, Trento, Italy and Dipartimento di } \\
\text { Informatica e Comunicazione, Università Degli } \\
\text { Studi Del, Varese, Italy }\end{array}$ & $\begin{array}{l}\text { IoT: Vision, applications } \\
\text { and research } \\
\text { challenges (Review) }\end{array}$ & $\begin{array}{l}\text { Ad-Hoc Networks } \\
2012 ; 10(7): 1497-516\end{array}$ & 198 \\
\hline $\begin{array}{l}\text { J. Gubbi, R. Buyya, } \\
\text { S. Marusic, } \\
\text { M. Palaniswami }\end{array}$ & $\begin{array}{l}\text { Department of Electrical and Electronic } \\
\text { Engineering, University of Melbourne, Australia } \\
\text { and Department of Computing and Information } \\
\text { Systems, University of Melbourne, Australia }\end{array}$ & $\begin{array}{l}\text { IoT: A vision, architectural } \\
\text { elements, and future } \\
\text { directions (Article) }\end{array}$ & $\begin{array}{l}\text { Future Generation } \\
\text { Computer Systems } \\
2013 ; 29(7): 1645-60\end{array}$ & 166 \\
\hline Z. Shelby, C. Bormann & $\begin{array}{l}\text { Sensinode, Finland and Universität Bremen TZI, } \\
\text { Germany }\end{array}$ & $\begin{array}{l}\text { 6LoWPAN: The Wireless } \\
\text { Embedded Internet (Book) }\end{array}$ & Book 2009. p. 223 & 163 \\
\hline R. K. Ganti, F. Ye, H. Lei & IBM T. J. Watson Research Center, USA & $\begin{array}{l}\text { Mobile crowd-sensing: } \\
\text { Current state and future } \\
\text { challenges (article) }\end{array}$ & $\begin{array}{l}\text { IEEE Communications } \\
\text { Magazine } \\
2011 ; 49(11): 32-9\end{array}$ & 133 \\
\hline R. H. Weber & University of Zurich, Zurich, Switzerland & $\begin{array}{l}\text { IoT: New security and } \\
\text { privacy challenges (article) }\end{array}$ & $\begin{array}{l}\text { Computer Law and } \\
\text { Security Review } \\
\text { 2010;26 (1):23-30 }\end{array}$ & 124 \\
\hline
\end{tabular}

CIMS = Computer Integrated Manufacturing Systems, RFID= Radio frequency identification, IoT=Internet of Things

topic had appeared 10 years ago in 2005. Until 2014, the total world output in IOT research had reached only to a small figure of 6800 publications, $72.74 \%$ growth per annum. China ranks at the top among 12 leading world countries for its highest global publication share $(44.8 \%)$ in Io'T. The remaining 11 countries are distant cousins; their combined global publication share $(42.7 \%)$ is less than that of China. Their global share is in single digit varying from USA (8.04\%), Germany $(6.06 \%)$, Italy (5.19\%), UK (4.84\%), Spain (4.19\%), France $(3.46 \%)$, Taiwan $(2.53 \%)$, South Korea $(2.34 \%)$, Switzerland (2.16\%), Finland (2.03\%), and India $(1.87 \%)$ during 2005-2013.

Citation profile of IoT publications is not very exciting. Only $4 \%$ output in Io'T received citations in the range $11-300+$ during 2005-2014. Sixty-nine percent papers received 0 citation in 10 years and $27 \%$ between 1 and 10 citations in 10 years. Citation density of IoT publications averaged at 0.84 citations per paper per citation window-year. Both the indicators-citation distribution and citation density confirm that citation profile of IoT publications is indeed not very exciting.

At country level, Italy registered the highest citation impact per paper (average citations per paper [ACPP] 6.44) among the 12 most productive countries, followed by Switzerland (6.02), Finland (4.31), UK (3.71), Spain (2.99), USA (2.14), Germany (2.09), France (1.94), Taiwan (1.40), South Korea (1.38), and India (1.33). Though China appeared as the most productive country in IoT output, its ACPP was the lowest (1.00) during 2005-2014. Citation analysis on RCI also reveals a very similar picture. Italy tops the ranking with an RCI score of 3.28, followed by 
Switzerland (3.06), Finland (2.19), UK (1.89), Spain (1.52), USA (1.09), and Germany (1.06) during 2005-2014.

IoT combines research studies in computer science, engineering, social sciences, management, physics, and decision sciences. But their respective shares in IoT research differ significantly. Computer science contributed the highest publication share of $64.93 \%$, followed by engineering (43.01\%), social sciences (4.65\%), business, management and accounting (3.73\%), physics (2.94\%), and decision science $(2.72 \%)$ during 2005-2014.

These multi-disciplinary areas differ in terms of their citation impact. Decision sciences registered the highest citation impact per paper (3.72), followed by physics (2.78), computer science (2.41), business, management and accounting (2.11), engineering (1.81), and social sciences (1.61) during 2005-2014.

Subfields analysis reveals that the major emphasis in IoT has been on hardware (technology) with $43.87 \%$ share, followed by applications $(42.93 \%$ share), architectural aspects of technology (22.69\% share), security aspects ( $17.43 \%$ share), software (technology) $(7.10 \%$ share), privacy ( $6.13 \%$ share), business models $(0.85 \%$ share), governance $(0.62 \%$ share $)$ and legal aspects, and accountability ( $0.5 \%$ share).

Among significant keywords identified, the largest number of papers (5657) was on IoT, followed by Internet (3112), architecture (1538), RFID (1394), sensor network (1295), security (1185), wireless sensor network (722), sensor (572), internet protocol (649), etc.

The top 20 most productive organizations contributed $16.78 \%$ publications share, $25.63 \%$ citation share, registered an average productivity of 57.05 papers, average citations per paper of 3.0, average h-index of 5.80, and average share of international collaborative papers of $21.60 \%$ during 2005-2014.

In contrast, the top 20 most productive authors together contributed $6.13 \%$ publications share, $23.16 \%$ citation share, registered an average productivity of 20.85 papers, average citations per paper of 7.43 , average h-index of 4.10 , and average share of international collaborative papers of $36.69 \%$ during 2005-2014.

The 15 most productive journals together contributed $24.54 \%$ share to the total journal publication output in during 2005-2014, with the largest number of papers (55) published in Jisuanji Xuebao Chinese Journal of Computers, followed by International Journal of Distributed Sensor Network (50), Sensors
Switzerland (46), China Communication (34), Wireless Personnel Communication (33), IEEE Sensors Journal (28), IEEE Transactions on Industrial Informatics (27), Ad-Hoc Networks (26), etc., during 2005-2014.

In all, there were 10 highly cited papers with citations from 124 to 1259 perpaper, and together they got 2951 citations. These highly cited papers came from 8 countries and had seen participation by 24 institutions and 41 authors during 2005-2014.

\section{Financial Support and Sponsorship}

Nil.

\section{Conflicts of Interest}

There are no conflicts of interest.

\section{REFERENCES}

1. Schoenberger CR. The Internet of Things. Forbes Magazine; March 18, 2002.

2. Gershenfeld N. When Things Start to Think. New York: Henry Holt and Company; 1999.

3. European Commission. Internet of Things - An Action Plan for Europe. COM; 2009. p. 278. Available from: http://www.eur-lex. europa.eu/LexUriServ/site/en/com/2009/com2009_0278en01. pdf.2009. [Last accessed on 2015 Jul 11].

4. Fleisch E, Mattern F, editors. Das Internet der Dinge. Springer; 2005. Available from: http://www.link.springer.com/book/10.1007/3540-28299-8. [Last accessed on 2015 Jul 11].

5. Floerkemeier $\mathrm{C}$, Langheinrich M, Fleisch E, Mattern F, Sarma SE, editors. First International Conference, IOT 2008, Zurich, Switzerland, March 26-28, 2008, Springer; 2008. Available from: https://www.books.google.co.jp/books/about/The_Internet_of_ Things.html. [Last accessed on 2015 Jul 12].

6. International Telecommunication Union: The Internet of Things; 2009. Available from: http://www.eur-lex.europa.eu/LexUriServ/site/en/ com/2009/com2009_0278en01.pdf. [Last accessed on 2015 Jul 11].

7. Fortino G, Trunfio P, editors. Internet of Things Based on Smart Objects. Technology, Middleware and Applications. Springer International; 2014. Available from: http://www.springer.com/gp/ book/9783319004907. [Last accessed on 2015 Jul 11].

8. Porter MF, Heppelmann A. How Smart, Connected Products Transferring Competition. Harvard Business Review; November, 2014. Available from: https://www.hbr.org/2014/11/how-smartconnected-products-are-transforming-competition. [Last accessed on 2015 Jul 11].

9. What is the internet of things? When things add value. In: Auto-ID Labs White Paper WP-BIZAPP-053, Auto-ID Lab. Switzerland: ETH Zurich/University of St. Gallen; 2010.

10. Mattern F, Floerkemeier C. From the Internet of Computers to the Internet of Things. Available from: http://www.vs.inf.ethz.ch/publ/ papers/Internet-of-things.pdf. [Last accessed on 2015 Jul 11].

11. Whitmore A, Agarwal A, Li DX. The Internet of things - A survey of topics and trends. Inf Syst Front 2015;17:261-74.

12. WIPO. Internet of Things Patent Landscape Analysis. Available from: http://www.wipo.int/patentscope/en/programs/patent_ landscapes/documents/internet-of-things.pdf. [Last accessed on 2015 Jul 11].

13. Eight Great Technologies. The Internet of Things; A Patent Overview. Newport, UK: Intellectual Property Office; 2014. 